\title{
Temporal and Spatial Variations in Body Size of Chum Salmon in Hokkaido
}

\author{
Fumi Yamaguchi, Taro Nakamura, and Hirokazu Urabe
}

\begin{abstract}
Salmon and Freshwater Fisheries Research Institute, Hokkaido Research Organization, 3-373 Kitakashiwagi,
\end{abstract} Eniwa, Hokkaido 061-1433, Japan

Keywords: body size, chum salmon, condition factor

In Hokkaido, chum salmon (Oncorhynchus keta) is one of the most commercially important species. A decline in body size of Hokkaido chum salmon has been reported over the last century, and density-dependent growth had been suggested as a possible cause (Ishida et al. 1993; Kaeriyama 1998). Changes in body size relate to both behavioral and physiological traits such as survival, number of eggs per body, and mating success in many marine fish species. These changes may cause fisheries problems, one example being a reduction of recruitment. The coastal catch of chum salmon in Hokkaido has been decreasing in recent years, however, trends and geographic variation of decline are uncertain. To understand the biological condition deeply, we analyzed the changes in body size of chum salmon in Hokkaido.

To measure changes in chum salmon body size we collected data from 18 rivers in Hokkaido: the Tokushibetsu, Tokoro, Abashiri, Shari, Shibetsu, Nishibetsu, Kushiro, Tokachi, Utabetsu, Shizunai, Shikiu, Yurappu, Moheji, Shiriuchi, Toshibetsu, Chitose, Shokanbetsu, and Teshio. From 2000-2018, fork lengths and body weights were measured, and 100 scale samples were taken (50 fishes per sex) once every 10 days during spawning season. Fulton's condition factor was estimated $\left(\mathrm{K}=\mathrm{BW}(\mathrm{kg}) / \mathrm{FL}(\mathrm{cm})^{3} \times 10^{6}\right.$, BW: body weight, FL: fork length). After outliers were removed by Smirnov-Grubbs' test $(p<0.05)$, over 400,000 individual data were used for the following analysis. Age- and sex-specific means in one sampling of each river were weighted by the number of catches in the river and the estimated mean size of the year. Ages were estimated using scales. Linear regressions between each length, weight, and condition factor with year were examined in each river. From this size-year regression, regression coefficients with significant slope $(p<0.05)$ were used for the examination of the size-dependent decline of body size. The regression coefficient and mean body length, or weight of 18 years in each river, were used for linear regression. For clustering analysis, condition factors in each river were scaled and analyzed using Ward's method.
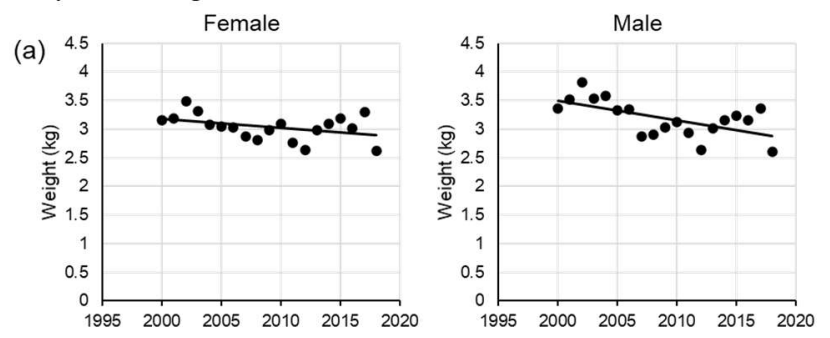

Fig. 1. Linear regression of mean body size in age- 4 chum salmon in Chitose River. Panel shows (a) body weight, (b) fork length, and (c) condition factor. Condition factors were estimated by the relationship between body weight and fork length.
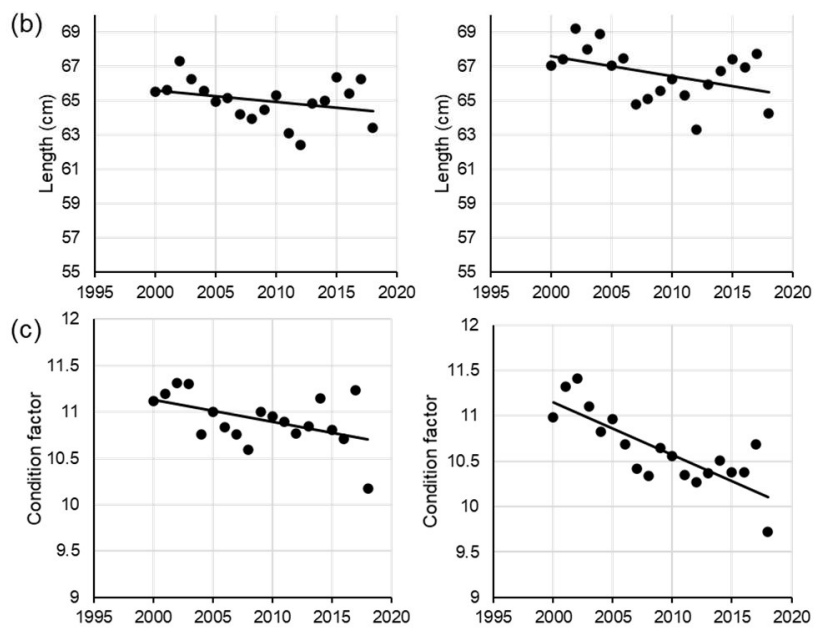

Declines in body weight and condition factor were detected among 17 rivers and fork length was found to have decreased among 16 rivers (Fig. 1). The average weight loss of age-3 (i.e., 0.2 in the European system), age-4 
and age- 5 fish were $0.029 \mathrm{~kg}, 0.036 \mathrm{~kg}$, and $0.052 \mathrm{~kg}$ per year, respectively. The average loss of condition factor was $0.058-0.060$ per year in chum salmon aged 3-5. The slopes of the regression line for 18 years were negatively correlated with average body weight, which might mean a size-dependent decline of body size (Fig. 2). Using Ward's hierarchical cluster analysis, indefinite groups were constructed among rivers according to temporal variation of each fork length and body weight. Compared to length and weight, variation in condition factor uncovered two more distinct groups in both sexes, southern and northern groups. The southern group contained populations in the Northeastern and Northwestern Pacific Ocean areas and the Nishibetsu River. The northern group consisted of the Okhotsk Sea area, the northern Japan sea area, and the Shibetsu River.

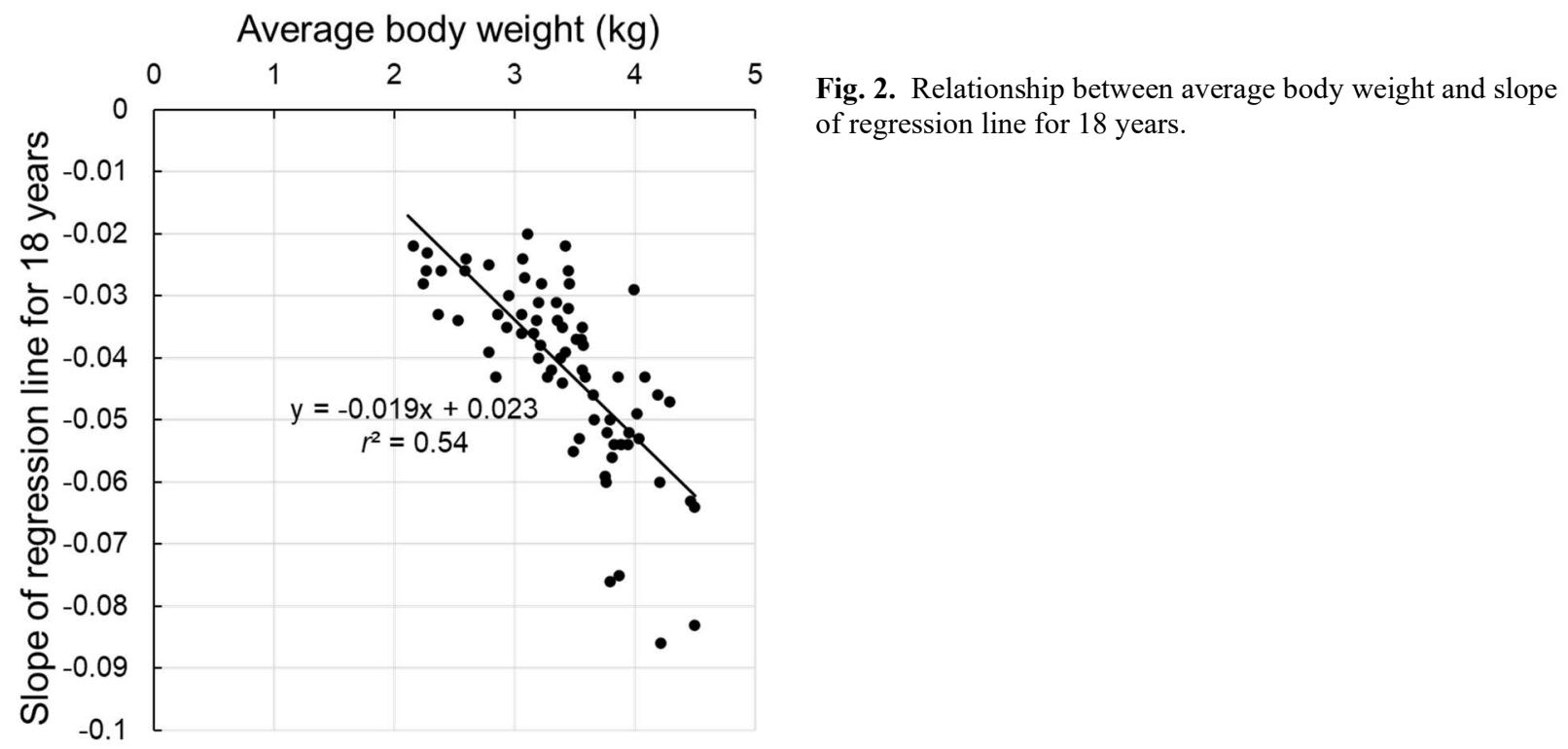

Because any further analysis using environmental or ecological data did not proceed this study, the reason for body size decline has not been uncovered. Both the individual and population size of chum salmon in Hokkaido during the last century was negatively correlated with an increase in fish releases (Kaeriyama 1998; Ishida et al. 1993) and density-dependent competition was suggested as one of the causes. Recently, however, the number of releases from Hokkaido have been stable and commercial catches have been decreasing. Decreasing return rate suggests intraspecific competition is not the major cause of the recent decrease in body size.

\section{REFERENCES}

Ishida, Y., S.O. Ito, M. Kaeriyama, S. McKinnell, and K. Nagasawa. 1993. Recent changes in age and size of chum salmon (Oncorhynchus keta) in the North Pacific Ocean and possible causes. Can. J. Fish. Aquat. Sci. 50: 290-295.

Kaeriyama, M. 1998. Dynamics of chum salmon, Oncorhynchus keta, populations released from Hokkaido, Japan. N. Pac. Anadr. Fish Comm. Bull. 1: 90-102. (Available at https://npafc.org) 